\title{
The effects of communication on the occurrence of the tyranny of the majority under voting by veto
}

\author{
Jan Sauermann ${ }^{1}$ (i)
}

Received: 23 October 2019 / Accepted: 7 June 2020 / Published online: 13 June 2020

(c) The Author(s) 2020

\begin{abstract}
The tyranny of the majority is one of the most frequently discussed problems of democracy in political theory. It arises when winning majorities are fixed and permanent, and there are no checks on the majority's ability to dominate the minority. In this paper, I investigate the effects of communication on the occurrence of majority domination. Theoretically, communication cuts both ways. On the one hand, forming and maintaining a coalition requires coordination between individuals, which is barely accomplishable without opportunities to communicate. On the other hand, communication strengthens prosocial orientations in groups and should thus prevent the permanent exclusion of minorities. I argue that publicity of communication is crucial. The prosocial effects of communication dominate when communication is public whereas exclusive majorities form under private communication. I test my claim in a series of laboratory experiments where five-member committees make distributional decisions using the voting mechanism 'voting by veto'. Compared to a baseline treatment without communication, groups distribute benefits more equally when they have the opportunity to communicate in a public chat. When communication is private, however, majoritarian coalitions form that exclude a minority of group members from the distribution of benefits.
\end{abstract}

\section{Introduction}

One of the most frequently discussed troubles of democracy is the tyranny of the majority (e.g. Madison [1787] 1945; Mill 1863, 13). If we think of politics as distributional conflicts of who gets what, when, and how (Lasswell 1936), democratic decision-making procedures frequently divide societies into winners and losers.

Electronic supplementary material The online version of this article (https://doi.org/10.1007/s0035 5-020-01268-w) contains supplementary material, which is available to authorized users.

Jan Sauermann

jan.sauermann@uni-koeln.de

1 Cologne Center for Comparative Politics, University of Cologne, Cologne, Germany 
Majority tyranny arises when winning majorities are fixed, and when there are no checks on the majority's ability to dominate the minority (Guinier 1994, 4). Hence, the tyranny of the majority can be defined as the permanent exploitation of the minority by the majority in democratic decisions over time. ${ }^{1}$

In this paper, I explore the effects of communication on the occurrence of the tyranny of the majority. From a theoretical perspective, communication cuts both ways. On the one hand, building and maintaining a coalition requires intensive coordination efforts among its members. Communication certainly greatly facilitates the identification of possible coalition partners. Moreover, it enables coalitions to arrange a common voting strategy and agree on a distribution of benefits among its members. On the other hand, a large body of research shows that communication strengthens prosocial orientations within groups (Bicchieri 2002; Ostrom 1998; Sally 1995). As majority domination implies the exclusion of minorities and thus rests on the expression of predominantly egoistic motivations, majority tyranny becomes less likely in the presence of communication when minorities have a voice.

Deliberative theory identifies publicity as one of the most important elements of deliberative processes (Thompson 2008, 510). Accordingly, I argue that the effect of communication depends on whether actors communicate in a public or a private arena. My argument follows Goodin (1986) who points out that individuals formulate their preferences in collective deliberations depending on the institutional environment. Certain types of arguments that may be highly effective in private deliberations, simply cannot be articulated in a public arena. Hence, individuals will launder their own preferences and express only prosocial, ethical preferences in public settings and refrain from expressing egoistic arguments. Elster (1986) argues in a similar direction stating that it is almost impossible to make egoistic arguments in public debates. Thus, public discussion tends to promote the common good. In light of this theoretical reasoning, I hypothesize that discussion in public arenas attenuates incentives to permanently exclude minorities from the distribution of benefits whereas private communication promotes the occurrence of the tyranny of the majority.

I test my hypothesis in a laboratory experiment where five-member groups have to make distributional decisions using the 'voting by veto' [VBV] mechanism developed by Mueller (1978). VBV consists of two stages, where in the first stage, every group member proposes a distribution. Voters' proposals are complemented with an additional alternative serving as a fallback option in case group members cannot reach a decision. At the beginning of the second stage, a random mechanism determines the order of voting after which group members sequentially eliminate one alternative each. When all group members have vetoed an alternative, a single winning alternative remains. As I show below, VBV inheres both majoritarian as well as egalitarian tendencies. The voting rule thus offers an ideal setting for studying in how far communication affects the occurrence of the tyranny of the majority versus distributionally fair group choices.

\footnotetext{
1 In accordance with Guinier (1994, 6), I argue that majority tyranny can only be avoided when minority voters have a chance to influence outcomes. Hence, conceding formal participatory rights to the minority is insufficient as long as the minority's interests are not at least partially reflected in collective decisions.
} 
My experiment consists of three treatments. The No-chat-treatment serves as a baseline where groups interact without the possibility to communicate. In the other two treatments, groups can communicate via a chat function. In the Public-chattreatment, all chat messages exchanged within the group can be seen by all group members. In the Private-chat-treatment, group members can determine which other group members receive a message. Hence, individuals have the opportunity to exclude other group members from the discussion.

The experimental results largely confirm the theoretical expectations. Communication in a public chat leads to more equally distributed proposals and outcomes in comparison to the baseline treatment. The tyranny of the majority, however, only occurs under private communication when individuals exclude other group members from the conversation. The analysis of chat protocols reveals that individuals bar other group members from the discussion when trying to build a coalition that excludes others from the distribution of benefits. When all messages are public, however, fairness arguments dominate.

\section{Related literature}

This study makes several important contributions to the literature. For one, it adds new empirical evidence on the workings of VBV. As I will explain below, VBV inheres some theoretical properties that might make it a suitable collective decisionmaking mechanism for small groups facing intense conflicts. To the best of my knowledge, however, the mechanism has never been implemented in any real-world decision and the only existing empirical evidence on its workings comes from a small number of laboratory experiments. For instance, Yuval (2002) and Yuval and Herne (2005) investigate voting strategies of group members in the second stage of VBV and find that most subjects apply myopic strategies vetoing one's worst alternative. Sauermann and Beckmann $(2017,2019)$ focus on the distributional effects of VBV. In the experiments, subjects interact anonymously without the opportunity to communicate within groups. The results show that larger groups choose more equal distributions than smaller groups. Individual behavior in group decisions seems to be motivated by a combination of material self-interest and social preferences such as reciprocity and fairness. How communication affects distributional fairness in decisions under VBV, however, has never been systematically investigated.

Furthermore, this study contributes to the empirical political economy literature on the effects of communication in collective decision making and bargaining. For instance, Andreoni and Rao (2011) find that communication influences altruistic behavior in a dictator game experiment by emphasizing empathy. Moreover, communication enhances equal distributions of benefits and raises fairness perceptions in the ultimatum game (Sulkin and Simon 2001). Simon and Sulkin (2002) investigate communication in an experimental 'divide the dollar' game. Their results show that computerized communication via a chat function brings about more equitable and fairer outcomes. Sauermann (2020) studies experimental committee decisions by majority rule where group members have the opportunity to communicate in a group chat. Group discussions are dominated by a 
consensual style and arguments about fairness, and almost all group decisions result in the selection of alternatives providing an equal distribution of benefits among committee members. Kittel, Luhan and Morton (2014) study the effect of communication on costly voting in multi-party elections experiments and find that communication improves coordination among group members raising turnout levels and increasing the proportion of strategic voting.

Agranov and Tergiman (2014) investigate communication via a chat function in a Baron and Ferejohn (1989) multilateral bargaining game. The chat tool allows subjects to send messages to any subset of group members. Hence, similar to my procedures in the Private-chat-treatment, it is possible to exclude group members from the discussions. In comparison to a baseline treatment without communication, the presence of the chat function leads to more unequal distributions. In fact, communication strengthens proposer power by reducing uncertainty about the minimal acceptable share of benefits that other group members are willing to accept. Furthermore, communication creates competition among group members to accept lower offers of proposers. The experiment by Baranski and Kagel (2015) yields similar results. Proposer power even further increases when voters can communicate with the proposer, but communication between voters is precluded. In a recent study, Agranov and Tergiman (2019) show that communication has the opposite effect under unanimity rule when competition between voters to be included in the coalition is absent. When group members can communicate, proposers appropriate smaller shares of resources and the equal split emerges as the dominant outcome of group choices.

Two recent experimental studies examine the effects of publicity of communication. Baron et al. (2017) conduct a laboratory experiment on the effects of communication on the formation and stability of coalitions in a three-person bargaining game under majority rule. In comparison to a baseline treatment without communication, private communication leads to more majoritarian outcomes excluding one group member from the distribution of benefits. Under public communication, however, universal outcomes dominate. Pronin and Woon (2017) also experimentally vary the publicity of communication. In a public goods game, they compare a treatment with public chat communication and a treatment enabling private chat communication prior to the public discussion. Pronin and Woon hypothesize that considerations of fairness and common interest will be prevalent when discussion is fully public, whereas egoistic behavior will be stronger when private communication is allowed. Their results, however, show that private communication has hardly any effect on behavior. In both treatments, groups choose rather equal outcomes at the beginning of the experiment, but over time form majority coalitions that exploit the minority.

Overall, the existing experimental evidence on the effects of the publicity of communication is inconclusive. My study offers an innovative perspective on the evolution of the tyranny of the majority by employing a novel institutional setting for group decisions. Moreover, Pronin and Woon use a stranger matching procedure and re-shuffle group composition after every period. I define majority tyranny as the permanent exclusion of the minority. Therefore, I use an experimental setting where group membership remains stable over time. The following section outlines my experimental design. 


\section{Experimental design}

In my experiment, I assign subjects to five-member committees and play a 'divide the dollar' game. The task is to divide 100 points among the members of the group. The experiment is programmed in z-Tree (Fischbacher 2007) and all between-subject interactions happen via a computer network. Moreover, throughout the whole experiment I use a neutral framing without referring further meaning to the context of the decision. Hence, group members are labeled Participant A, B, C, D, and E.

Groups decide democratically over the distribution of the 100 points using Mueller's (1978) 'voting by veto' voting mechanism. Decision making under VBV consists of two stages. In the first stage, all group members propose a distribution of the 100 points among the committee members. Individuals may only assign nonnegative integer numbers of points to other group members and the sum of points distributed in a proposal must not exceed 100. When all five group members have submitted their proposals, the computer automatically adds a sixth alternative that assigns zero points to all participants. Hence, if committees choose this automatically generated status quo alternative, the 100 points will be destroyed and all voters earn nothing. Analogously to Mueller (1978, 58-59), I model the 100 points as a net gain in comparison to the existing status quo that will be forfeited if the group cannot reach a decision.

At the beginning of the second stage, the computer randomly determines the order of voting and announces it to the group. ${ }^{2}$ Then voters sequentially eliminate one alternative each. After all committee members have exercised their veto, a single alternative remains. This alternative is the outcome of the group decision, and committee members receive the number of points assigned to them in the winning alternative.

In order to be able to examine the occurrence of the tyranny of the majority, which I defined above as the permanent exclusion of the minority from the distribution of benefits, groups play the game repeatedly for 15 periods. I use a partnermatching procedure to assign individuals into groups. Hence, the composition of committees and the labeling of group members remain constant throughout the whole experiment. At the end of the experiment, subjects fill out a questionnaire supplying demographic data as well as political and social attitudes. As a measure to avoid wealth effects and to increase the salience of individual decisions in periods, I use a random payoff mechanism. Thus, the computer randomly selects three periods at the end of the experiment and subjects receive $€ 0.16$ for every point earned in these periods.

The experiment consists of three treatments varying participants' opportunities to communicate with other members of their committee. As explained above, groups interact exclusively via a computer network. Hence, in all treatments there

\footnotetext{
${ }^{2}$ Determining the voting order randomly after the first stage ensures that group members do not have an incentive to misrepresent their preferences. As group members do not know the order of voting when making their proposals they have an incentive to state their proposals sincerely, as well as to rank sincerely the other group members' proposals in the voting stage (Felsenthal and Machover 1992, 224).
} 
Table 1 Illustration of the egalitarian tendencies of VBV

\begin{tabular}{llll}
\hline & Voter 1 & Voter 2 & Voter 3 \\
\hline Proposal of Voter 1 & 90 & 5 & 5 \\
Proposal of Voter 2 & 20 & 60 & 20 \\
Proposal of Voter 3 & 30 & 30 & 40 \\
Status quo & 0 & 0 & 0
\end{tabular}

Prediction: Proposal of Voter 3 for voting sequences $1-2-3,1-3-2$, 2-1-3, 3-1-2, 3-2-1

Proposal of Voter 2 for voting sequence $2-3-1$

is no direct verbal communication within committees during the experiment. The No-chat-treatment reduces communication as far as possible and precludes all interactions between group members besides making proposals and voting on them. In the other two treatments, participants can communicate with other members of their group via a computerized chat tool. The chat tool is available in both stages of the decision-making process, and all chat messages exchanged during the experiment are recorded. In the Public-chat-treatment, all chat messages are public and can be received by all group members. The Private-chat-treatment differs from the Public-chat-treatment in only a single detail. Here, participants can send messages to any subset of members of their committee. Hence, subjects can decide whether they want to exclude others from the conversation and send a private message to a single other group member or a particular subset of group members. Of course, subjects can also send public messages that are delivered to the whole group.

\section{Theoretical properties of voting by veto}

Voting by veto has several interesting theoretical properties. For instance, it satisfies neutrality, that is, no alternative-including the existing status quo-has a structural advantage under the voting rule. Moreover, decision making under VBV always yields a unique winning alternative, and hence, VBV is decisive. The potential to form and maintain coalitions among group members and the expected distributions of benefits in VBV decisions depend on individuals' opportunities to coordinate behavior with other group members. As I will explain in the following, VBV inheres two divergent tendencies. When coordination is not possible, the voting mechanism promotes distributional fairness and should result in equal distributions of benefits. On the other hand, VBV inheres majoritarian tendencies when participants are able to coordinate and form coalitions. In this study, I exploit the theoretical ambiguity of VBV to test in how far public and private communication promote the egalitarian or majoritarian tendencies of the decision mechanism.

Table 1 illustrates the egalitarian tendencies of $\mathrm{VBV}^{3}$ In the example, a threemember group distributes 100 points. I assume that committee members make

\footnotetext{
${ }^{3}$ For a formal analysis of the incentive structure of VBV see Mueller (1978), Felsenthal and Machover (1992), and Moulin (1982).
} 
Table 2 Illustration of the majoritarian tendencies of VBV

\begin{tabular}{llll}
\hline & Voter 1 & Voter 2 & Voter 3 \\
\hline Proposal Voter 1 & 34 & 33 & 33 \\
Proposal Voter 2 & 0 & 50 & 50 \\
Proposal Voter 3 & 0 & 50 & 50 \\
Status Quo & 0 & 0 & 0 \\
\hline
\end{tabular}

Prediction: Proposal of Voter 2 or proposal of Voter 3 for all possible voting sequences

proposals and vote without being able to coordinate their behavior with other voters. Rational voters will use backwards induction when deciding how to use their veto. For example, if the voting sequence is $1-2-3$, we have to consider the decision calculus of Voter 3 at the last step of the voting sequence first. We know that Voter 3's least preferred alternative - the status quo-will be vetoed by Voter 3 if it survives until the last step of the voting sequence. Hence, it can never be the final outcome of the group decision, and the other voters do not have to consider it when making their vote choices. Likewise, the proposal of Voter 1 cannot win, because it is the least preferred alternative of Voter 2 out of the remaining three alternatives at the second step of the sequence. This leaves Voter 1 with an effective choice between the proposals of Voter 2 and Voter 3 at the first step of the voting sequence. She will veto the proposal of Voter 2 because she prefers Voter 3's proposal, which will be the outcome of the group decision.

In the example, the predicted outcome-the proposal of Voter 3-is the most equally distributed alternative among all proposals. This is no coincidence. Five out of six possible voting sequences select the proposal of Voter 3, and the voting sequence 2-3-1 results in the selection of Voter 2's proposal-the second-most equal distribution of benefits. In general, Mueller $(1978,66)$ formally demonstrates that the probability of the selection of the proposal promising the most even distribution of benefits to all voters approaches 1 when group size increases. ${ }^{4}$ The intuition behind the attractiveness of equal proposals is simple. Equal proposals rank relatively high in all group members' preference rankings. Hence, equal alternatives have a low probability of being vetoed. Moreover, group members whose own proposals have already been vetoed earlier in the decision-making process will work for the success of equally distributed alternatives. Playing the game repeatedly further strengthens the egalitarian tendencies of VBV. As only the two most equally distributed proposals have a chance to become the group choice, repetition induces competition among committee members to make more equally distributed proposals (Mueller 1978, 66-67). From a normative perspective, VBV might offer an innovative collective decision-making mechanism for moderating conflicts by fostering consensual group choices (Oppenheimer 2012, 218).

\footnotetext{
4 The probability that an $n$-member group will select the most equally distributed proposal is $1-\frac{n-2}{n(n-1)}$ (Mueller 1978, 66). For $n=5$ as in this experiment, the probability is thus $85 \%$.
} 
VBV's egalitarian tendencies critically hinge on the assumption that group members cannot coordinate their behavior. However, when we assume that voters can form coalitions, predicted outcomes change radically, and the majoritarian tendencies of VBV become apparent. Table 2 provides an example where Voter 2 and Voter 3 coordinate their proposals and agree to split the 100 points among themselves while excluding Voter 1 from the distribution of benefits. In the example, the result of the decision will be either the proposal of Voter 2 or the proposal of Voter 3 irrespective of the voting sequence. Voters 2 and 3 can use their two vetoes to eliminate the proposal of Voter 1 and the status quo. Consequently, one of their own proposals will survive regardless of how Voter 1 uses her veto. Hence, when at least half of the group forms a coalition, there is no way to prevent the majority from excluding the minority from the distribution of benefits. VBV thus inhibits a clear potential for majoritarian tendencies when coordination among group members is possible.

I expect that the strength of the majoritarian and egalitarian tendencies of VBV will differ in the experimental treatments. Thus, the majoritarian tendencies should be strongest in the Private-chat-treatment. Here, the chat function facilitates coordination among committee members, and individuals can utter egoistic arguments in private. In comparison, VBV's egalitarian tendencies should be stronger in the No-chat-treatment and the Public-chat-treatment, but for different reasons. The absence of communication in the No-chat-treatment exacerbates the formation of majority coalitions whereas in the Public-chat-treatment, coordination is possible in principle, yet the publicity of communication should promote the common good according to deliberative democratic theory. However, it remains an empirical question whether the egalitarian effect will be stronger in the No-chat-treatment or the Public-chat-treatment.

\section{Experimental results}

The experiment was conducted in the Cologne Laboratory for Economic Research in 2017 and 2018. Subjects were recruited randomly via ORSEE (Greiner 2015) from a subject pool comprising about 4500 potential participants. Overall, 410 subjects participated in the study. 90 subjects formed 18 groups in the No-chat-treatment, 115 subjects participated in the Public-chat-treatment forming 23 groups, and 205 subjects formed 41 groups in the Private-chat-treatment. I use a typical student sample in the experiment. Hence, 407 participants were enrolled as students of the University of Cologne. Participants were on average about 24 years old and $54.4 \%$ were female. Students from economics and management formed the largest sub-group $(44.9 \%)$ in the experiment.

At the beginning of the experiment, subjects were randomly assigned to cubicles in order to avoid uncontrolled interactions among participants. Subjects received 
Table 3 Classification of group choices

\begin{tabular}{llll}
\hline Type of chosen distribution & No chat & Public chat & Private chat \\
\hline Equal split & $83.7 \%$ & $89.3 \%$ & $72.4 \%$ \\
Majority tyranny & $1.9 \%$ & - & $21.3 \%$ \\
Rotating 100 & - & $5.8 \%$ & $3.3 \%$ \\
Status quo & $1.1 \%$ & - & $0.2 \%$ \\
Other & $13.3 \%$ & $4.9 \%$ & $2.8 \%$ \\
$N$ & 270 & 345 & 615 \\
\hline
\end{tabular}

Equal split: Every group member receives 20 points

Majority tyranny: Three group members each receive at least 30 points

Rotating 100: Every group member receives 100 points once over the course of five period

Status quo: Selection of automatically generated fallback option

written instructions explaining the rules of the experiment. ${ }^{5}$ Potential inquiries were answered privately. After reading the instructions, subjects filled in a brief questionnaire testing their understanding of the procedures. Then decision making started. On average, the experiment took about $60 \mathrm{~min}$ in the No-chat-treatment and $70 \mathrm{~min}$ in both communication treatments. Subjects earned on average $€ 17.30$ during the experiment including $€ 4.00$ paid as a lump-sum for arriving at the laboratory on time.

\subsection{Classification of group choices}

As a first step of the data analysis, I classify the outcomes of group decisions in the three treatments according to the chosen distributions. Table 3 shows that the equal split, i.e. 20 points for all group members, is the modal group choice in all three treatments. In the No-chat-treatment, $83.7 \%$ of all decisions result in an equal split of the 100 points indicating that VBV's egalitarian tendencies are strong in this treatment. I define majority tyranny as chosen distributions where a majority of three group members each receive at least 30 points. The majority thus obtains at least $90 \%$ of the distributional amount. ${ }^{6}$ In the No-chat-treatment, only 5 out of 270 decisions (1.9\%) result in such a majoritarian distribution. ${ }^{7}$ Obviously, forming a coalition is very difficult when communication among group members is restricted to only making proposals and voting. On the other hand, groups have no problems avoiding the selection of the computer-generated status quo. Only three decisions $(1.1 \%)$ end with the destruction of the 100 points

\footnotetext{
5 English translations of the instructions can be found in the supplementary materials A.

6 Supplementary materials B replicates the analyses using a stricter threshold of $99 \%$. Results change only marginally.

7 Majority tyranny occurred in two groups in the No-chat-treatment. One group chose the majoritarian distribution in a single period. Another group chose majority tyranny in the last four periods of the experiment.
} 
in the No-chat-treatment. Finally, a substantial number of decisions (13.3\%) do not fall within the aforementioned categories. In comparison to the two communication treatments, there is considerable noise in the chosen outcomes of the No-chat-treatment.

VBV's egalitarian tendencies are even stronger in the Public-chat-treatment. In 308 out of 345 decisions (89.3\%), groups choose an equal split of the 100 points. Even more remarkably, not a single decision results in a majoritarian coalition. As hypothesized above, the tyranny of the majority does not occur when communication is public. Outcomes classified as Rotating 100 result from rather complex decision processes. Here, committees agree that every group member will receive the entire distributional amount of 100 points once over the course of five periods while the other four group members receive 0 points. When the assignment of 100 points rotates among all group members, the expected value of this strategy, 20 points per period, is also equally distributed among all voters. Certainly, risk seeking is the main driving motive behind the 20 decisions classified as Rotating 100 in the Public-chat-treatment. However, egalitarian motives probably also play a role in these group decisions, because the expected value of that particular scheme is equally distributed among committee members.

No decision ends in the selection of the status quo in the Public-chat-treatment. The remaining 17 decisions $(4.9 \%)$ fall into the residual category, and eight of them stem from a single committee where one group member publicly proposed to form a coalition and exclude two other group members from the distribution of benefits. The other four voters unanimously argued that this would be very unfair and strongly rejected the proposal in the public group chat. However, when the first group member insisted and continued the coalition building attempts for several periods, the other committee members finally reacted and formed a four-member coalition that excluded that group member from the distribution of points. Hence, even though the committee ultimately made unequal choices, the chat protocol clearly reveals that these decisions were driven by fairness considerations of voters who punished another group member for making unfair proposals in the public chat. Overall, VBV's egalitarian tendencies dominate in the vast majority of decisions in the Public-chat-treatment.

The Private-chat-treatment offers a different picture, even though the equal split is also the modal outcome in the treatment occurring in $72.4 \%$ of all decisions. Most importantly, majority tyranny is much more prevalent in the Privatechat-treatment than in the other two treatments. In 131 group decisions $(21.3 \%)$ a three-member coalition forms and excludes the other two committee members from the distribution of benefits. Above, I define majority tyranny as the permanent exclusion of the minority from the distribution of benefits, and indeed, coalitions in the Private-chat-treatment are remarkably stable. Majoritarian coalitions occur in 13 out of 41 groups. The average duration of a coalition is 8.5 periods. Only two coalitions are terminated during the experiment and replaced by a new one consisting of a partially different membership. Most coalitions are built in the early phase of the experiment, 12 are formed during the first 4 periods. To conclude, I find clear evidence that private communication promotes the formation of durable majority coalitions. 
Table 4 Individual characteristics of majorities, minorities, and coalition initiators in majority tyranny decisions

\begin{tabular}{|c|c|c|c|c|}
\hline & \multirow{2}{*}{$\begin{array}{l}\text { Private-chat- } \\
\text { treatment }\end{array}$} & \multicolumn{2}{|l|}{ Majority tyranny } & \multirow{2}{*}{$\begin{array}{l}\text { Initiators of } \\
\text { majority coali- } \\
\text { tions }\end{array}$} \\
\hline & & Majority & Minority & \\
\hline Male participants & $46.8 \%$ & $\mathbf{6 3 . 6 \%}(0.001)^{\mathrm{a}}$ & $51.9 \%(0.162)^{\mathrm{a}}$ & $68.4 \%(0.001)^{\mathrm{a}}$ \\
\hline Economics students & $48.3 \%$ & $\mathbf{6 0 . 1 \%}(0.001)^{\mathrm{a}}$ & $\mathbf{3 8 . 2} \%(0.003)^{\mathrm{a}}$ & $84.2 \%(0.001)^{\mathrm{a}}$ \\
\hline Left-right self-placement & 3.5 & $3.6(0.138)^{\mathrm{b}}$ & $3.1(0.351)^{b}$ & $3.84(0.167)^{\mathrm{b}}$ \\
\hline Guess in guessing game & 48.6 & $46.9(0.939)^{\mathrm{b}}$ & $45.6(0.918)^{\mathrm{b}}$ & $36.8(0.037)^{b}$ \\
\hline Offer in dictator game & 12.2 & $9.4(0.013)^{\mathrm{b}}$ & $16.9(0.220)^{\mathrm{b}}$ & $4.7(0.007)^{\mathrm{b}}$ \\
\hline
\end{tabular}

Bold values highlight significant differences in comparison to the average value in the whole treatment ${ }^{a} p$-value from two-tailed binomial test comparing value to the average-value in the treatment ${ }^{\mathrm{b}} p$-value from two-tailed Fisher-Pitman permutation test comparing sample to remaining individuals in the treatment

\subsection{Membership characteristics of majorities, minorities, and initiators of coalitions in majority tyranny}

A substantial number of decisions in the Private-chat-treatment result in the formation of majoritarian coalitions that exclude a minority from the distribution of benefits. As a next step, I analyze the characteristics of members of the majority and the minority in these group choices and the characteristics of group members that first proposed to form a majoritarian coalition in a group's chat. ${ }^{8}$ As Table 4 shows, the share of male participants in the Private-chat-treatment is $46.8 \%$. By comparison, males are significantly more likely to be members of a majoritarian coalition (63.6\%). Men are also slightly overrepresented among the excluded group members $(51.9 \%)$. However, the difference is not significant according to general scientific standards. I also find that students from economics, management or related fields are significantly overrepresented among members of the majority $(60.1 \%)$ and underrepresented among the minority (38.2\%) in comparison to the share of economics students in the whole treatment. Furthermore, I tested whether individual political orientations affect the propensity to enter a coalition. I measure left-right self-placement on a 7-point Likert-scale where 1 corresponds to the extreme left, 4 represents the center and 7 matches the extreme right. My results show that members of the majority have slightly more right-wing political orientations. However, differences are small and do not reach commonly accepted levels of significance.

After the 15 group decisions, but before receiving information about their final payouts, subjects played two additional incentivized games, a guessing game and a dictator game. These two games provide behavioral measures for participants' level of reasoning and the strength of their prosocial preferences for a fair distribution.

\footnotetext{
${ }^{8}$ I only analyze the Private-chat-treatment because the majority tyranny only occurs in this treatment.
} 
I use them to test in how far these characteristics affect the likelihood to become a member of a majoritarian coalition.

In the guessing game (Nagel 1995), subjects have to choose a number from the interval 0-100. The group member whose guess is closest to two-thirds of the average guess of all five group members earns an additional payoff of 50 points. The unique Nash-equilibrium of the game can be found by repeatedly eliminating weakly dominated strategies. Guesses higher than 66.67 are weakly dominated because twothirds times the average guess must always be lower than 66.67. If players take this into account, all numbers above $2 / 3 * 66.67=44.44$ are weakly dominated. Iterating this process leads to the Nash-equilibrium where all players guess 0 . However, individuals will only play the equilibrium if they are perfectly rational themselves and if rationality is common knowledge. The guessing game thus offers a behavioral measure of subjects' level of reasoning. Lower guesses then indicate higher abilities to think ahead paired with beliefs in higher strategic abilities of other subjects.

After completing the guessing game, participants play a dictator game in order to measure subjects' prosociality. In this two-player game, the proposer divides a fixed amount of 50 points between herself and a passive second player, the responder (see Forsythe et al. 1994; Kahneman et al. 1986). ${ }^{9}$ Game theory predicts that purely egoistically motivated subjects will offer 0 points to the responder. Positive offers thus indicate a prosocial orientation of individuals and measure in how far subjects take the well-being of other group members into account.

The results in Table 4 show that guesses in the guessing game of committee members from groups where majority tyranny occurs do not differ significantly from all participants in the Private-chat-treatment. Guessed numbers of members of the majority (46.9) and members of the minority (45.6) are only marginally lower than the treatment average (48.6). Hence, individual level of strategic reasoning and the propensity to form a majoritarian coalition are not interrelated. However, I find a significant relationship between voters' behavior in the voting decisions and the dictator game. Members of majoritarian coalitions offer on average 9.4 points and thus significantly less than the average offer in the Private-chat-treatment (12.2 points). Excluded group members offer more points (16.9 points), yet the difference is not significant at conventional standards. Overall, my results suggest a systematic relationship between prosocial motivations and the propensity to become a member of a majoritarian coalition. The occurrence of the tyranny of the majority is less likely when prosocial motivations among committee members become stronger.

The last column of Table 4 shows individual characteristics of initiators of majority coalitions. A coalition initiator is the group member that started the first coalition formation attempt within a group and suggested to exclude other group members from the distribution of benefits in a group's chat. Based on the content of their chat

\footnotetext{
${ }^{9}$ I employ a strategy method such that participants play the game as both proposers and responders. A random draw determines whether points are actually converted into money after the experiment. The probability that points earned as a proposer or as a responder are paid out is 20 percent each.
} 
messages, I identify 19 coalition initiators in the Private-chat-treatment out of which 12 were successful and resulted in the formation of a majority coalition. ${ }^{10}$ The individual characteristics of initiators differ substantially from the other participants in the treatment. Hence, male participants (68.4\%) and economics students (84.2\%) are significantly overrepresented among initiators. Moreover, initiators display slightly more right-wing political orientations than other participants in the treatment do. The behavioral measures of the guessing game and the dictator game also reveal interesting findings. Average guessed numbers of initiators of majority coalitions (36.8) are significantly lower than average guesses in the Private-chat-treatment. Moreover, their average offers in the dictator game (4.7) are significantly lower. Hence, the results suggest that egoistic group members with a high level of strategic reasoning and strong beliefs in others' strategic abilities play a crucial role in the formation of majoritarian coalitions and the emergence of the tyranny of the majority. ${ }^{11}$

\subsection{Majoritarian and egalitarian tendencies of voting by veto}

In order to analyze committee decision making in greater detail, I look at the development of proposals and group choices over time. As a visualization of the relative strength of VBV's majoritarian and egalitarian tendencies in the three treatments, Fig. 1 displays the average number of points of the two lowest offers in group members' proposals and the average number of points of the two lowest payoffs in the group decisions. ${ }^{12}$ If the egalitarian motives are strong, i.e. if proposals and group choices provide an equal distribution of points, the index approaches 20 points. When majority tyranny prevails, i.e. a majority of three group members excludes the other two group members from the distribution of points, the index converges on $0 .{ }^{13}$

Panel A of Fig. 1 shows the development of proposals. As can be seen, egalitarian tendencies dominate at the beginning of the experiment. In all three treatments, the two lowest point assignments in subjects' proposals amount to about 19 points on average. In the following periods, proposals in the No-chat-treatment and the Private-chat-treatment become more majoritarian, while proposals in the Publicchat-treatment remain very egalitarian until the end of the experiment. Overall, the two worst-off group members are offered on average 18.8 points in the Public-chattreatment, and thus significantly more than voters in the No-chat-treatment (16.8 points, $p=0.001$, two-tailed Fisher-Pitman permutation test for two independent samples) and group members in the Private-chat-treatment (15.8 points, $p=0.012$,

\footnotetext{
${ }^{10}$ In the Public-chat-treatment, I identify four coalition initiators, which all failed to form a majority coalition. The low number of cases does not allow for meaningful statistical analyses.

11 In a recent coalition formation experiment, Sauermann, Schwaninger and Kittel (2020) find similar evidence. Farsighted and self-interested subjects are more likely to form stable majoritarian coalitions than more myopic group members.

12 Consider a proposal or a group choice $18-12-25-36-9$. In the example, the average of the two lowest numbers of points (12 and 9) is 10.5 points.

13 Figure 1 omits all decisions where groups choose Rotating 100. Rotating 100 decisions bias the results in the direction of majoritarian tendencies. As I have shown above, however, alternative risk-seeking and egalitarian motivations underlie these group choices.
} 


\section{(A) Proposals}

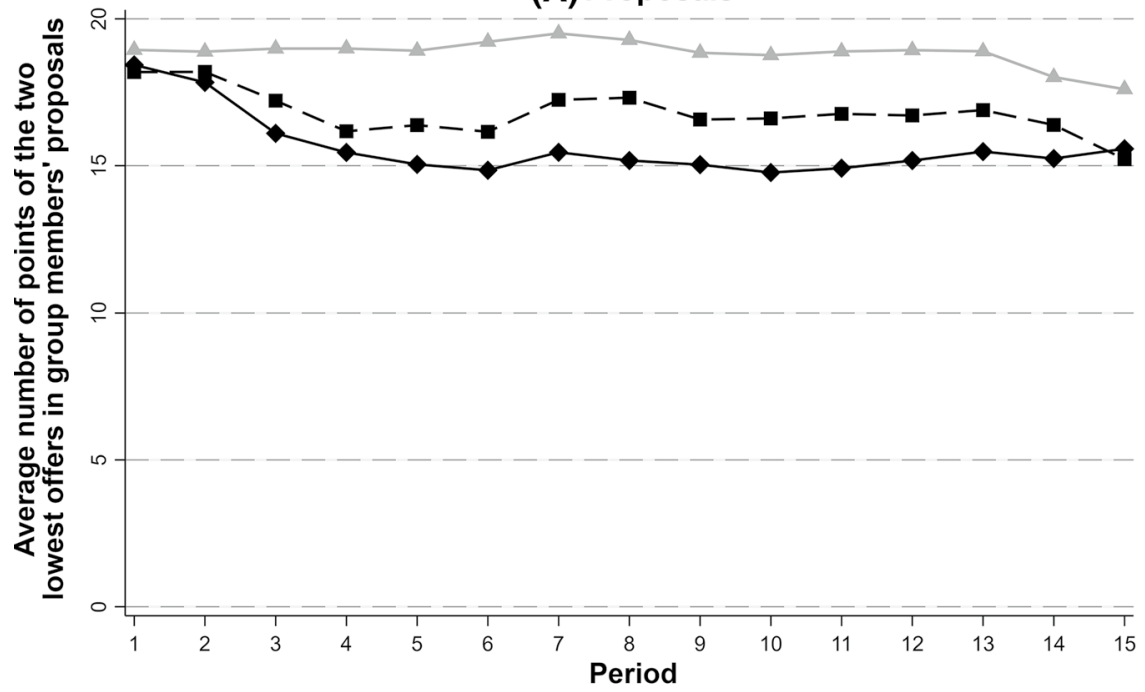

(B) Chosen distributions

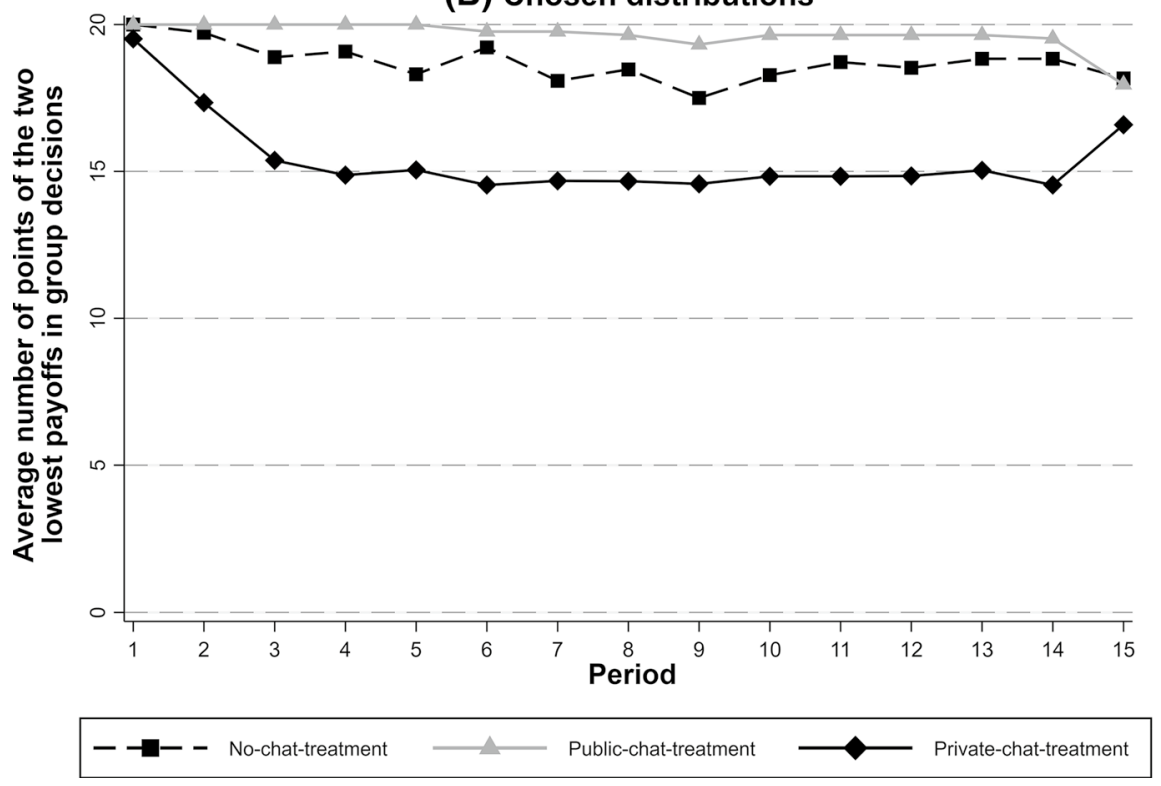

Fig. 1 Majoritarian and egalitarian tendencies in the group decisions

two-tailed Fisher-Pitman permutation test for two independent samples). A twotailed Fisher-Pitman permutation test for two independent samples, however, indicates no significant difference between the No-chat-treatment and the Private-chattreatment $(p=0.503)$. 
Table 5 Classification of chat messages

\begin{tabular}{lll}
\hline Type of chat message & Public-chat-treatment & Private-chat-treatment \\
\hline Irrelevant & $1991(74.7 \%)$ & $5148(70.5 \%)$ \\
Relevant & $673(25.3 \%)$ & $2156(29.5 \%)$ \\
Inclusive/fair & $485(18.2 \%)[72.1 \%]$ & $648(8.9 \%)[30.1 \%]$ \\
Exclusive/egoistic & $108(4.1 \%)[16.0 \%]$ & $1305(17.9 \%)[60.5 \%]$ \\
Other & $80(3.0 \%)[11.9 \%]$ & $203(2.8 \%)[9.4 \%]$ \\
$N$ & 2664 & 7304 \\
\hline
\end{tabular}

Irrelevant: Messages not directly related to group decision making (weather, jokes, etc.)

Relevant: Messages related to group decision making

Inclusive/fair: Prosocial arguments, fairness

Exclusive/egoistic: Forming and maintaining majority coalitions

Percentage share of all messages in parentheses

Percentage share of relevant messages in brackets

Panel B shows the outcomes of group decisions. VBV's egalitarian tendencies dominate in the first period of the experiment. Almost all committee decisions in all three treatments result in an equal split of the 100 points, and the two worstoff group members thus earn on average about 20 points. Equality remains at very high levels in the Public-chat-treatment. Over the whole experiment, the two worstoff group members earn on average 19.7 points. Chosen outcomes are significantly more majoritarian in the No-chat-treatment (18.7 points, $p=0.051$, two-tailed Fisher-Pitman permutation test for two independent samples) and even more so in the Private-chat-treatment (15.8 points, $p=0.006$, two-tailed Fisher-Pitman permutation test for two independent samples). The difference between the No-chattreatment and the Private-chat-treatment is weakly significant ( $p=0.064$, two-tailed Fisher-Pitman permutation test for two independent samples).

To conclude, the analysis of VBV's egalitarian and majoritarian tendencies offers a coherent picture. In accordance with my theoretical expectations, majoritarian tendencies are strongest in the Private-chat-treatment. In the No-chat-treatment, where the absence of direct communication impedes coordination among group members the egalitarian tendencies become stronger. Hence, publicity of communication has the strongest treatment effect in the experiment. In the following, I will analyze in how far this effect is reflected in the content of chat messages.

\subsection{Analysis of chat protocols}

In accordance with deliberative democratic theory, I argue that egoistic arguments can only be made in private conversations and individuals will express prosocial arguments in public arenas. In order to assess the prevalence of different types of messages, I classify all chat messages in the two communication treatments according to their content. Table 5 displays my findings. As a first step, I differentiate between relevant and irrelevant chat messages. Relevant messages are directly related to the decision-making process. For example, groups discuss 
Table 6 Character of chat messages in the Privatechat-treatment by number of recipients

\begin{tabular}{llll}
\hline $\begin{array}{l}\text { Number of receivers } \\
\text { of a message }\end{array}$ & Inclusive/fair & Exclusive/egoistic & $N$ \\
\hline 4 & $546(88.2 \%)$ & $73(11.8 \%)$ & 619 \\
3 & $4(28.6 \%)$ & $10(71.4 \%)$ & 14 \\
2 & $76(9.2 \%)$ & $746(90.8 \%)$ & 822 \\
1 & $22(4.4 \%)$ & $476(95.6 \%)$ & 498 \\
\hline
\end{tabular}

possible distributions, try to build coalitions, or talk about the workings of the decision mechanism. Irrelevant messages are not related to the group choice in a narrow sense. Group members, for example, pass time by telling jokes, talk about the weather, or the food in the cafeteria. ${ }^{14}$ As Table 5 shows, most content of group discussions is not directly related to the group choice. Hence irrelevant messages amount to $74.7 \%$ of all messages in the Public-chat-treatment and $70.5 \%$ in the Private-chat-treatment. The share of relevant and irrelevant messages does not differ significantly between treatments $(p=0.652$, two-tailed Fisher-Pitman permutation test for two independent samples). ${ }^{15}$

Among the relevant messages, I differentiate between inclusivelfair, exclusive/ egoistic, and other messages. A message is classified as inclusive if subjects make prosocial arguments about fairness and including all group members in the distribution benefits. When subjects talk about forming or maintaining a coalition that excludes other committee members, I classify the message as exclusive / egoistic. Most messages in the residual category deal with the speed of decision making. Table 5 reveals that the content of relevant messages varies considerably in the two communication treatments. In the Public-chat-treatment, $72.1 \%$ of all relevant messages contain inclusive and prosocial arguments while the share of fair messages in the Private-chat-treatment is only $30.1 \%$ and thus significantly lower $(p=0.003$, two-tailed Fisher-Pitman permutation test for two independent samples). On the other hand, exclusive/egoistic arguments only amount to $16.0 \%$ of all relevant messages in the Public-chat-treatment. In the Private-chat-treatment, however, it is the largest category containing $60.5 \%$ of all relevant chat content. Again, the difference between treatments is significant ( $p=0.006$, two-tailed Fisher-Pitman permutation test for two independent samples).

In the Private-chat-treatment, voters can send chat messages to any subset of members of their group. Subjects can thus decide whether they want to send a public

\footnotetext{
14 I do not deny the fact that messages classified as irrelevant might also have some effect on group decision making. Thus, conversations about apparently trivial issues might create a sense of group solidarity or a common identity among committee members.

15 The relatively high share of irrelevant chat messages is due to the fact that group members have the opportunity to use the chat throughout the whole 15 periods of the experiment. When a group has already come to a decision in a period, but has to wait for other groups to finish decision making as well, group members frequently use the chat to kill time. However, it is important to notice that all groups actually use the chat function in the experiment and only four group conversations do not contain relevant messages.
} 
message to all committee members or exclude others from the conversation. Table 6 displays the content of relevant messages by the number of recipients. When subjects send a public message to all other committee members, most of the content $(88.2 \%)$ is about fairness of the group choice and including all group members in the distribution of benefits. As theoretically expected, egoistic arguments are mostly put forward in private. When subjects selectively communicate with one or two other group members, more than $90 \%$ of all relevant messages are about coalition formation and the exclusion of other group members from the distribution of benefits.

Overall, the analyses of the content of chat protocols reveals a consistent relationship between the institutional settings in which communication takes place on the content of conversations. I find strong empirical evidence for Goodin's (1986) and Elster's (1986) theoretical reasoning that egoistic arguments cannot be articulated in a public arena. Public communication promotes prosocial and fair arguments whereas individuals express exclusive and egoistic aspects in private conversations.

\section{Conclusion}

From a theoretical perspective, communication has ambiguous expected effects on the occurrence of the tyranny of the majority. On the one hand, communication greatly facilitates within group coordination and thus the formation and maintenance of coalitions. On the other hand, communication promotes the common good and the exclusion of minorities. In this study, I argue that publicity moderates the effect of communication in group decisions. As it is not possible to make egoistic arguments in public without adverse consequences, open communication promotes the inclusion of all group members and thus an equal distribution of benefits. Private communication, however, is expected to facilitate majoritarian coalitions. I test this argument in a series of laboratory experiments where committees make purely distributional decisions deciding by VBV. My results clearly confirm that VBV's egalitarian tendencies dominate when communication among group members is public whereas the tyranny of the majority only occurs under private communication. Moreover, I show that inclusive and fair arguments dominate in private discussions while group members express predominantly exclusive and egoistic arguments when they have the opportunity to exclude other committee members from the conversation.

My findings have important implications for the real-world applicability of VBV. Because of its potential egalitarian tendencies, VBV could provide a workable decision mechanism in contexts where groups face fierce conflicts by offering incentives for consensual decision making. This study, however, empirically demonstrates VBV's liability to fall prey to the tyranny of the majority. Therefore, a final assessment of VBV's possible real-world applications clearly requires further research on the workings of the mechanism.

The experimental results add a new perspective on pluralist theory of democracy according to which societies consisting of various groups, where no single group constitutes a majority of the whole population, should be able to avoid the 
permanent exploitation of minorities because existing majorities can always be defeated by alternative coalitions (Miller 1983). From this perspective, ruling majorities are expected to alternate, leading to an equitable distribution of benefits over time. In my experiment, I study groups without any pre-existing lines of division among group members and still majority tyranny does occur when group members have the opportunity to communicate privately. This finding demonstrates the importance of various modes of communication in collective decisions.

Overall, my experiment shows that public deliberation fosters prosociality in group decisions whereas private discussion promotes majoritarian outcomes. The generalizability of this finding, however, has to be evaluated in light of recent contributions on the effects of publicity and transparency in decision-making processes. Several other studies also show that openness and transparency have positive normative implications in various contexts. De Fine Licht (2014), for example, finds that individuals who perceive political decision-making procedures to be transparent ascribe higher levels of procedural fairness to decisions and are more likely to accept them. Likewise, Juhl and Hilpert (2019) conduct a survey experiment and show that non-transparent decision procedures decrease the level of approval of an agreement independent of the actual content of the outcome. Moreover, a laboratory experiment by Morton and Ou (2019) reveals that individuals are more likely to vote for prosocial alternatives when voting is public in comparison to secret voting.

Of course, publicity of political decision procedures is not desirable under all circumstances. The best example is the secret ballot as a protection of voters against coercion and intimidation. Furthermore, a formal model by Stasavage (2007) demonstrates that the effect of publicity in group decisions is context-dependent. In negotiations between representatives of different sub-groups, public debate might increase polarization and conflict instead of creating consensus. Representatives have incentives to signal loyalty to their own group and therefore be less prepared to compromise. Chambers (2004) also argues that the harmful effects of publicity have been under-theorized in deliberative democratic theory. Questions of public versus private arenas have to be addressed depending on context. Further empirical explorations of these contexts certainly provide interesting opportunities for future research.

Acknowledgements Open Access funding provided by Projekt DEAL. This project is funded by the German Research Foundation (SA 3139/1-1). Financial support from the German Research Foundation for the Cologne Laboratory for Economic Research is also gratefully acknowledged. Furthermore, I am very grateful to Paul Beckmann and Anne Kailuweit for excellent research assistance. I would also like to thank seminar and presentation participants at Bremen, Oxford, and EPSA (Belfast) for many helpful comments on prior versions of this manuscript.

Open Access This article is licensed under a Creative Commons Attribution 4.0 International License, which permits use, sharing, adaptation, distribution and reproduction in any medium or format, as long as you give appropriate credit to the original author(s) and the source, provide a link to the Creative Commons licence, and indicate if changes were made. The images or other third party material in this article are included in the article's Creative Commons licence, unless indicated otherwise in a credit line to the material. If material is not included in the article's Creative Commons licence and your intended use is not permitted by statutory regulation or exceeds the permitted use, you will need to obtain permission 
directly from the copyright holder. To view a copy of this licence, visit http://creativecommons.org/licen ses/by/4.0/.

\section{References}

Agranov M, Tergiman C (2014) Communication in multilateral bargaining. J Publ Econ 118:75-85

Agranov M, Tergiman C (2019) Communication in bargaining games with unanimity. Exp Econ 22(2):350-368

Andreoni J, Rao JM (2011) The power of asking: How communication affects selfishness, empathy, and altruism. J Publ Econ 95(7-8):513-520

Baranski A, Kagel JH (2015) Communication in legislative bargaining. J Econ Sci Assoc 1(1):59-71

Baron DP, Bowen TR, Nunnari S (2017) Durable coalitions and communication: Public versus private negotiations. J Publ Econ 156:1-13

Baron DP, Ferejohn JA (1989) Bargaining in legislatures. Am Political Sci Rev 83(4):1181-1206

Bicchieri C (2002) Covenants without swords. Group identity, norms, and communication in social dilemmas. Rationality Soc 14(2):192-228

Chambers S (2004) Behind closed doors: publicity, secrecy, and the quality of deliberation. Political Philosophy 12(4):389-410

de Fine Licht J (2014) Transparency actually: How transparency affects public perceptions of political decision-making. Euro Political Sci Rev 6(2):309-330

Elster J (1986) The market and the forum: three varieties of political theory. In: Elster J, Hylland A (eds) Foundations of social choice theory. Cambridge University Press, Cambridge, pp 103-132

Felsenthal DS, Machover M (1992) Sequential voting by veto: making the Mueller-Moulin algorithm more versatile. Theor Decis 33(3):223-240

Fischbacher U (2007) z-Tree: Zurich toolbox for ready-made economic experiments. Exp Econ 10(2):171-178

Forsythe R, Horowitz JL, Savin NE, Sefton M (1994) Fairness in simple bargaining experiments. Games Econ Behav 6(3):347-369

Goodin RE (1986) Laundering preferences. In: Elster J, Hylland A (eds) Foundations of social choice theory. Cambridge University Press, Cambridge, pp 75-101

Greiner B (2015) Subject pool recruitment procedures: organizing experiments with ORSEE. J Econ Sci Assoc 1(1):114-125

Guinier L (1994) The tyranny of the majority: fundamental fairness in representative democracy. Free Press, New York

Juhl S, Hilpert D (2019) Wheeling and dealing behind closed doors: estimating the causal effect of transparency on policy evaluations using a survey experiment. Political Sci Res Methods Online First. https:// doi.org/10.1017/psrm.2018.67

Kahneman D, Knetsch JL, Thaler RH (1986) Fairness and the assumptions of economics. J Business 59(4, pt. 2):S285-S300

Kittel B, Luhan WJ, Morton RB (2014) Communication and voting in multi-party elections: an experimental study. Econ J 124:F196-F225

Lasswell HD (1936) Politics: Who gets what, when, how. Whittlesey House, New York

Madison J (1945) Federalist 10. In: Hamilton A, Madison J, Jay J (eds) The federalist papers. The Heritage Press, New York

Mill JS (1863) On liberty. Ticknor and Fields, Boston

Miller N (1983) Pluralism and social choice. Am Political Sci Rev 77(3):734-747

Morton RB, Ou K (2019) Public voting and prosocial behavior. J Exp Political Sci 6(3):141-158

Moulin H (1982) Voting with proportional veto power. Econometrica 50(1):145-162

Mueller DC (1978) Voting by veto. J Publ Econ 10(1):57-75

Nagel R (1995) Unraveling in guessing games: an experimental study. Am Econ Rev 85(5):1313-1326

Oppenheimer JA (2012) Principles of politics. A rational choice theory guide to politics and social justice. Cambridge University Press, Cambridge

Ostrom E (1998) A behavioral approach to the rational choice theory of collective action [Presidential Address, American Political Science Association, 1997]. Am Political Sci Rev 92(1):1-22

Pronin, K., \& Woon, J. (2017). Public deliberation, private communication, and collective choice. Working Paper. 
Sally D (1995) Conversation and cooperation in social dilemmas. A meta-analysis of experiments from 1958 to 1992. Rationality Soc 7(1):58-92

Sauermann J (2020) Pro-sociality and the uncovered set: Why is majority rule stable?. In: Paper presented at the 2018 EPSA annual conference, Vienna.

Sauermann J, Beckmann P (2017) 'Divide the dollar' using voting by veto. In: Linhart E, Debus M, Kittel B (eds) Jahrbuch für Handlungs- und entscheidungstheorie, vol 10. Springer, Wiesbaden, pp 85-109

Sauermann J, Beckmann P (2019) The influence of group size on distributional fairness under voting by veto. Eur J Polit Econ 56:90-102

Sauermann J, Schwaninger M, Kittel B (2020) Making and breaking coalitions: strategic foresight and prosociality in majority decisions. In: Paper presented at the 2019 EPSA annual conference, Belfast.

Simon AF, Sulkin T (2002) Discussion's impact on political allocations: an experimental approach. Polit Anal 10(4):403-412

Stasavage D (2007) Polarization and publicity: rethinking the benefits of deliberative democracy. J Polit 69(1):59-72

Sulkin T, Simon AF (2001) Habermas in the lab: a study of deliberation in an experimental setting. Polit Psychol 22(4):809-826

Thompson DF (2008) Deliberative democratic theory and empirical political science. Ann Rev Polit Sci 11:497-520

Yuval F (2002) Sophisticated voting under the sequential voting by veto. Theor Decis 53(4):343-369

Yuval F, Herne K (2005) Sophisticated behavior under majoritarian and non-majoritarian voting procedures. Polit Behav 27(3):217-237

Publisher's Note Springer Nature remains neutral with regard to jurisdictional claims in published maps and institutional affiliations. 